10

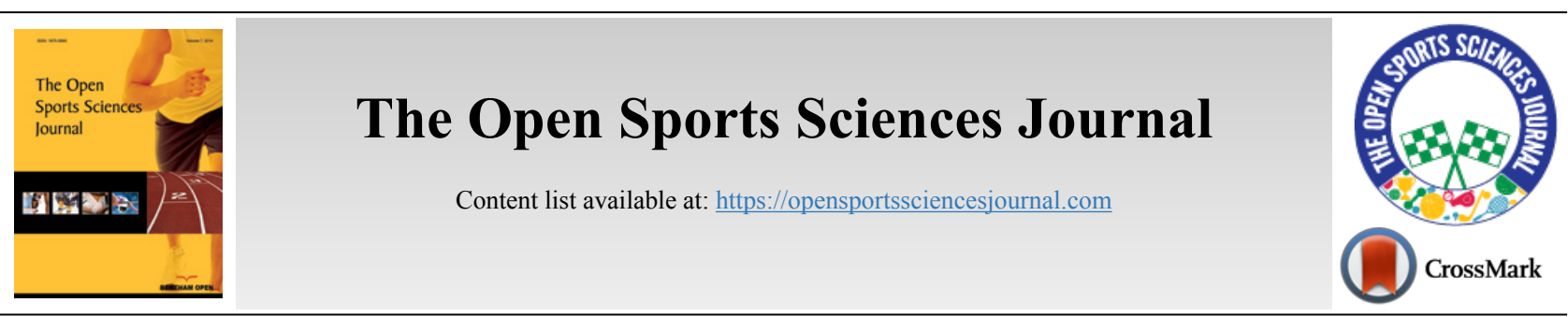

RESEARCH ARTICLE

\title{
Energy Cost and Energy Sources of an Elite Female Soccer Player to Repeated Sprint Ability Test: A Case Study
}

Fabrizio Perroni ${ }^{1}$, Gian Pietro Emerenziani ${ }^{2}$, Fabrizio Pentenè ${ }^{3}$, Maria Chiara Gallotta ${ }^{4}$, Laura Guidetti ${ }^{4}$ and Carlo Baldari ${ }^{1, *}$

${ }^{1}$ Faculty of Psycology, eCampus University, Novedrate, Como, Italy

${ }^{2}$ Department of Experimental and Clinical Medicine, University of Magna Graecia of Catanzaro, Catanzaro, Italy

3 “Roma CF” Soccer team, Rome, Italy

${ }^{4}$ Department of Movement, Human and Health Sciences, University of Rome “Foro Italico”, Italy

\begin{abstract}
:
Background:

Intense physical efforts performed at maximal or near-maximal speeds and the ability to recover among sprint are important characteristics of a soccer player. In the last years, women's soccer has become a rapidly and markedly growing sport ( $+34 \%$ of new players from 2000 ).

Objective:

The aim of this case study was to analyse the performance (total time -TT; fatigue index percentage -IF\%) and physiological (aerobic and anaerobic) responses to Repeated Sprint Ability test (RSAt) of an elite female player.

\section{Methods:}

To identify the contribution of the 3 energy sources at the beginning, middle, and at the end of the different sprint of RSAt performance in a female player (age: 30 years; BMI: $\left.20.3 \mathrm{~kg} / \mathrm{m}^{2}\right)$, which requested $7 \times 30 \mathrm{~m}$ sprints $(25 \mathrm{~s}$ active recovery among sprints) with a change of direction, a portable metabolimeter and software dedicated were used. A repeated measure MANOVA over the 7 sprints time series was applied ( $\mathrm{p}<0.05)$.

Results:

Results showed that TT was 58.71 s (Ideal Time: 56.98 s) with IF\% of $3.0 \%$. Energy contributions were given for $80.3 \%$ by aerobic, $19.2 \%$ by anaerobic lactid, and $0.5 \%$ by anaerobic alactid sources. We have found different kinetics in the heart rate (HR) and maximum oxygen uptake with the oxygen uptake that reached the peak when HR was still rising.

\section{Conclusion:}

Considering that the energy consumption during intermittent exercises requires different metabolism as a result of physiological stimuli proposed, the present findings substantiate the need to choose specific and adequate training methods for female soccer players that aim at increasing their RSA performances.
\end{abstract}

Keywords: Aerobic source, Anaerobic source, Heart rate, Fatigue, RSA, MANOVA.

\begin{tabular}{|l|l|l|l|}
\hline Article History & Received: January 07, 2019 & Revised: March 05, 2019 & Accepted: March 12, 2019
\end{tabular}

\section{INTRODUCTION}

Soccer is a multifactorial sport that requires many physical (jogging, running, jumps, sprint, and direction and speed changes) and sport-specific activities (tackles, dribbling, pas-

\footnotetext{
* Address correspondence to this author at the Faculty of Psycology, eCampus University, Via Matera 18, Rome, Italy; Tel: +3495951881;

E-mail: carlo.baldari@uniecampus.it
}

sing, and shooting the ball) during a match. Intense physical efforts performed at maximal or near-maximal speeds and the ability to recover among sprint are important characteristics of soccer player [1]. Mohr et al. [2] showed better values of toplevel soccer players in fast-paced running and sprinting than their lower-level counterparts.

The Repeated Sprint Ability (RSA) is the ability to repeatedly produce maximal or near maximal sprint efforts 
$(\leq 10$ s) with brief $(\leq 60$ s) recovery intervals (rest or low/moderate activity) and it is considered an important indicator in talent identification [3 - 5]. It is related to both neuromuscular and metabolic factors [3, 6, 7]. Some researchers have redefined it as "repeated acceleration ability": i) as metabolically taxing accelerations do not always reach fixed sprinting thresholds [8] but are more likely to hit an individualized sprinting threshold; ii) player's aerobic capacity may not contribute to RSA as much as other physiological factors $[9,10]$.

In the last years, women's soccer has become a a rapidly and markedly growing sport ( $+34 \%$ of new players from 2000$)$ [11]. Lohmander et al. [12] declared that women's soccer was the second largest sport in Sweden with $20 \%$ of all soccer players registered being women. A recent UEFA report about Women's football across the national associations [13] showed: i) increase of registered female players (from 1.270 million in 2016 to 1.365 million in $2017 ;+7.5 \%$ in one year), ii) six countries (England, France, Germany, Netherlands, Norway, Sweden) with more than 100000 players, iii) more than doubled of professional and semi-professional soccer players in four years (from 1.680 in 2013 to 3.572 in 2017), iv) more qualified coaches trained by country soccer federation (from 17.553 in 2016 to 19.474 in 2017), qualified match officials (from 7.505 in 2013 to 12.785 in 2017), and women's youth teams (from 21.285 in 2013 to 35.183 in 2017).

For these reasons, the sports science community has increased its attention to this sector with studies that have investigated on the physical characteristics and performance responses of female match play to translate these data into specific training protocols [14] but there still exists a large disparity in the volume of studies involving male and female players. The aim of the present case study was to analyse the performance and physiological responses to Repeated Sprint Ability test (RSAt) by an elite female player. To our knowledge, this is the first time of utilization of an RSAt in female soccer players. The hypothesis is that there may be an important difference between energy contributions and that, given the differences in physiological and physical characteristics between genders, there may be a difference in RSA values in males previously studied in the literature with consequence of not being able to use the male reference parameters for the evaluation of fitness of female soccer players.

\section{MATERIALS AND METHODS}

\subsection{Subject}

A female soccer player (Age: 30 years; Weight: $60 \mathrm{~kg}$; Height: $1.72 \mathrm{~m}$; BMI: $20.3 \mathrm{~kg} / \mathrm{m}^{2}$;Body Fat: 14\%; Soccer Experience: $24 \mathrm{yrs}$ ) was recruited from the female club of Italian Soccer Federation (Roma CF; League "B"), with training volume of at least 3 days with the duration of $2 \mathrm{~h}$ per training session and a match per week, and volunteered to participate in this study. The participant was fit and healthy at the moment of data collection and reported no recent injuries. Considering that the exercise intensity in the RSAt protocols was extremely high, the reasons for using this female soccer player as the "case study" were i) her soccer training begun with male soccer players (from 6 to $14 \mathrm{yrs),} \mathrm{and} \mathrm{ii)} \mathrm{she} \mathrm{played}$ at high-level categories ("A", "B", and "C") from 15 years old. Her experiences as an elite female soccer player make her worthy of study that could be useful to increase the knowledge about the target of training to follow.

Written informed consent was received from the player after verbal and written explanation of the experimental design and potential risks of the study. She was free to withdraw from the study without any penalty for upcoming reason(s). All procedures performed were in accordance with the ethical standards of the institutional and/or national research committee and with the 1964 Helsinki declaration and its later amendments or comparable ethical standards.

The player agreed to provide her maximum will effort to perform at her best during the field test considered in this study.

\subsection{Procedures}

The female soccer player engaged in an experimental session organized in the first week of April 2017 during the competition period. Assessments (anthropometric and physiology evaluations) were performed in the same testing session, with 15 min rest among them, on the first training day after a soccer match (at least $48 \mathrm{~h}$ of recovery, between 16:00 $\mathrm{PM}$ and 18:00 PM) by an experienced investigator. The participant was instructed to avoid any other strenuous activity and training $24 \mathrm{~h}$ before the test.

To evaluate RSA performance, this study used a protocol of Bangsbo et al. [15] and, to reduce the weather conditions' influence (temperature: $18{ }^{\circ} \mathrm{C}$; humidity: $70 \%$ ), it was performed on an artificial turf [16], approved for national level competitions, with the participant who wore sports shoes. Before the test, a standard 15-minute warm-up of jogging at $40-60 \%$ of maximal heart rate $\left(\mathrm{HR}_{\max }\right)$ and strolling locomotion was performed.

Energy cost and energy source of an RSAt were evaluated using a portable metabolimeter (K5, Cosmed, Rome, Italy) while energetic profile during RSAt estimated by free software GEDAE-LaB [17] which uses the mathematical functions presented in previous studies $[18,19]$. Prior to the test session, the participant wore the metabolimeter during one training unit to familiarize with the test equipment. Percentages of individual $\mathrm{HR}_{\max }$ have been used as markers of exercise effort and grouped in five intensity categories (maximal effort: $>95 \%$ $\mathrm{HR}_{\max }$, high-intensity: $86-95 \% \mathrm{HR}_{\max }$, low-intensity: $76-85 \%$ $\mathrm{HR}_{\max }$, active recovery: $65-75 \% \mathrm{HR}_{\max }$, passive recovery: $\leq 65 \% \mathrm{HR}_{\max }$ ) to indicate the physical load imposed [20].

\subsection{Measurements}

\subsubsection{Anthropometrics}

Anthropometric measures were taken by an experienced researcher. Anthropometric values (weight and height) were measured with participants wearing only light clothes and barefoot using a digital scale $( \pm 0.1 \mathrm{~kg})$ and a fixed stadiometer $( \pm 0.1 \mathrm{~cm})$ instrument (Seca 702, Seca GmbH \& Co. KG, Hamburg, Germany). Body mass index (BMI) was used to 
assess weight relative to height and calculated by dividing body mass in kilograms by height in square meters $\left(\mathrm{kg} / \mathrm{m}^{2}\right)$.

\subsubsection{Repeated-sprint Ability Test}

In the present study, we used the repeated sprint ability test [15] which requested $7 \times 30 \mathrm{~m}$ sprints $(25 \mathrm{~s}$ active recovery among sprints) with a change of direction to the best of their abilities, decelerating as quickly as possible after the finishing line. The recovery aimed to cover a distance of $40 \mathrm{~m}$ (including deceleration phase) of jogging to return to the starting line for a new start (Fig. 1). Previously, 0.94, 0.99 and 0.84 were Intraclass correlation coefficients, power and effect size for this test, respectively.

To evaluate RSA performance, we used a dual infrared reflex photoelectric cell system (Polifemo, Microgate, Udine, Italy). According to the literature [7, 21], for the RSAt validation, the first sprint speed must not be less than $5 \%$ of the individual's best $30 \mathrm{~m}$ performance previously assessed. In this study, the sum of sprinting scores was considered as global RSA performance (total time, TT) [9], while the fatigue index percentage (IF\%) was calculated as follows [21]:

fatigue index $(\mathrm{IF} \%)=[($ total sprint time/lowest sprint time*7)*100] - 100)

During the test, HR (Sport Tester, Polar Electro, Kempele, Finland), blood lactate [bLa-] (Accusport Lactate Analyser, Roche, Basel, Switzerland), oxygen uptake $\left(\mathrm{VO}_{2}\right)$, carbon dioxide production $\left(\mathrm{VCO}_{2}\right)$, minute ventilation $(\mathrm{VE})$, and respiratory exchange ratio (RER) were measured (K5, Cosmed, Rome, Italy), and expiratory rate ratio was calculated. The K5 data showed intraclass reliability coefficients $>0.99$ [22]. The flow meter and gas analyzer were calibrated with a $3 \mathrm{~L}$ syringe (Hans Rudolph, Inc., Dallas, TX, USA), and with known gas mixtures $\left(\mathrm{O}_{2}: 16.0 \%\right.$ and $20.9 \% ; \mathrm{CO}_{2}: 5.0 \%$ and $\left.0.03 \%\right)$, respectively. The $\mathrm{K} 5$ metabolimeter was placed on the back to minimize interference during the performance, in particular, during the changes in direction. HR and ventilatory gases were collected after $5 \mathrm{~min}$ and before $6 \mathrm{~min}$ after the end of the test. HR values were recorded at every 5 seconds while ventilatory gases were recorded breath by breath.

Blood lactate [bLa-] was measured by using finger blood samples before the warm-up and, immediately, and at 3,6, and 9 min after the end of the test with a 0.999 intraclass reliability [23]. An alcohol swab was used to clean the area of blood withdrawal and the blood sample was drawn into the test strip (BM Lactate, Roche, Basel, Switzerland).

To identify the beginning and the end of the different sprint of RSAt, an experimenter pressed the marker button of the metabolimeter. The contribution of the 3 energy sources to the overall energy requirement of the RSA was determined using
$\dot{\mathrm{V}}_{2}$ measurement during and post-exercise and [bLa-] concentration data and, then, estimated by GEDAE-LaB. Despite the $\mathrm{VO}_{2}$ baseline $\left(\mathrm{VO}_{2}\right.$ rest $)$ can be assumed as a fixed value (i.e. $3.5 \mathrm{ml} \mathrm{kg}^{-1} \mathrm{~min}^{-1}$ ) [24], in this study we measured $\mathrm{VO}_{\text {2rest }}$ to calculate the aerobic system (AS). The anaerobic alactic system (AAS) is considered the fast component of excess post-exercise oxygen consumption. In the present study, we used a bi-exponential model after severe exercise domain [25] and, in order to analyse a possible impact of the time of recovery on the calculation of the AAS, the fast component of excess post-exercise oxygen consumption was determined using the $\dot{\mathrm{V}}_{2}$ data during $6 \mathrm{~min}$ of recovery. The anaerobic lactic system (ALS) was assessed using the oxygen equivalent from blood lactate accumulation, while alactic anaerobic system (AAS) was assessed by the fast component of excess post-exercise oxygen consumption. The energy expenditure and energy systems were expressed in liters of oxygen $\left(\mathrm{LO}_{2}^{-1}\right)$, kilojoules (caloric equivalents $=20.9 \mathrm{~kJ} \mathrm{LO}_{2}^{-1}$ ) and kilocalories (caloric equivalents $=5 \mathrm{~kJ} \mathrm{LO}_{2}^{-1}$ ). Total energy expenditure was calculated as the sum of the three energy systems (AS+AAS+ALS). In addition, the contributions of the three energy systems were also expressed as total energy expenditure percentage. Previously, $\mathrm{VO}_{2 \max }\left(2538 \mathrm{~mL}^{-1} \mathrm{~min}^{-1}\right)$ and $\mathrm{HR}_{\max }(189$ bpm) of female soccer player were assessed by training coach of soccer team through field intermittent test.

\subsection{Statistical Analyses}

Data are reported as means and standard deviations (mean $\pm \mathrm{SD}$ ), and 0.05 level of confidence was selected throughout the study. The RSAt responses of $\mathrm{HR}$ and $\mathrm{VO}_{2}$ were separately evaluated from data acquired breath-by-breath during the 7 sprints: for each sprint, the data were normalised to ten samples. Then a repeated measure MANOVA over the 7 sprints time series was applied. The Statistical package IBM SPSS (ver. 24, SPSS Inc., Chicago, IL, USA) was used to carry out statistical procedures.

\section{RESULTS}

Analysis of data showed that the total time of RSAt was $58.71 \mathrm{~s}$ (individual's best $30 \mathrm{~m}: 7.91 \mathrm{~s}$; Ideal Time: $56.98 \mathrm{~s}$ ) with a Fatigue Index of 3.0\%. Trend analysis of $\mathrm{HR}$ and $\mathrm{VO}_{2}$ during RSAt revealed that only HR showed a significant $(\mathrm{p}<0.001)$ trend over sprints series. Performance, $\mathrm{VO}_{2}$, $\% \mathrm{VO}_{2 \max }, \mathrm{HR}$, and $\% \mathrm{HR}_{\max }$ values of every single sprint recorded during RSAt are shown in Table $\mathbf{1 .}$

The HR increased abruptly at the beginning of the RSAt, fluctuated during the performance, and decreased smoothly during the recovery phase (Fig. 2).

Energy cost and energy source contribution during RSAt are reported in Table 2 . 


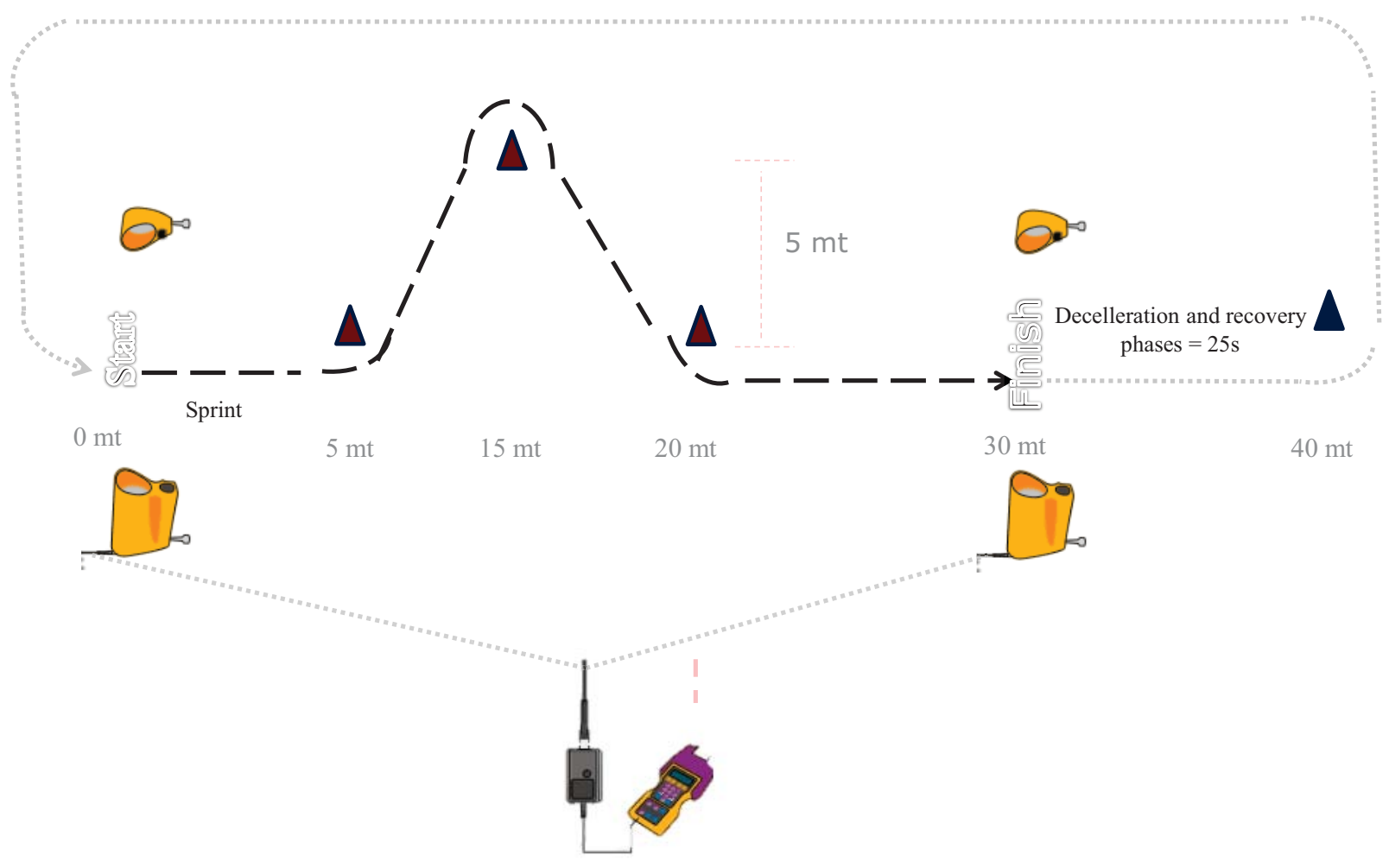

Fig. (1). Repeated Sprint Ability test.

Table 1. Time. oxygen consumption $\left(\mathrm{VO}_{2}\right)$. minute ventilation (VE), respiratory exchange ratio (RER) and heart rate (HR) of each single sprint recorded during RSAt.

\begin{tabular}{|c|c|c|c|c|c|c|c|c|c|c|c|c|c|c|c|c|c|c|c|c|}
\hline & \multirow[b]{2}{*}{ RSA (s) } & \multicolumn{3}{|c|}{$\mathrm{VO}_{2}\left(\mathrm{mLmin}^{-1}\right)$} & \multicolumn{3}{|c|}{$\% \mathrm{VO}_{2 \mathrm{Max}}$} & \multicolumn{3}{|c|}{ VE $\left(\operatorname{Lmin}^{-1}\right)$} & \multicolumn{3}{|c|}{ RER } & \multicolumn{3}{|c|}{ HR (beats min ${ }^{-1}$ ) } & \multicolumn{3}{|c|}{$\% \mathrm{HR}_{\text {Max }}$} & \multirow[b]{2}{*}{ Effort } \\
\hline & & Mean & \pm & St. Dev. & Mean & & St. Dev. & Mean & & St. Dev. & Mean & \pm & St. Dev. & Mean & & St. Dev. & Mean & \pm & $\begin{array}{c}\text { St. } \\
\text { Dev. }\end{array}$ & \\
\hline Rest & & 335 & \pm & 97 & 13 & $\exists$ & 4 & 35 & & 20 & 0.9 & \pm & 0.20 & 60 & I & 2 & 31 & & 1 & passive recovery \\
\hline $1^{\text {st }}$ Sprint & 8.2 & 2343 & \pm & 752 & 92 & I & 30 & 63 & \pm & 14 & 1.0 & \pm & 0.01 & 138 & \pm & 2 & 72 & \pm & 0 & active recovery \\
\hline $2^{\text {nd }}$ Sprint & 8.29 & 2445 & \pm & 483 & 96 & \pm & 19 & 78 & \pm & 15 & 1.1 & \pm & $0.02 *$ & 159 & \pm & $0^{*}$ & 84 & \pm & 0 & low-intensity \\
\hline $3^{\text {rd }}$ Sprint & 8.55 & 2438 & \pm & 196 & 96 & \pm & 8 & 89 & \pm & 7 & 1.3 & \pm & $0.03 *$ & 163 & I & $1 *$ & 86 & \pm & 0 & high-intensity \\
\hline $4^{\text {th }}$ Sprint & 8.67 & 2452 & \pm & 299 & 97 & \pm & 12 & 90 & \pm & 7 & 1.3 & \pm & $0.03 *$ & 164 & \pm & $1 *$ & 87 & \pm & 0 & high-intensity \\
\hline $5^{\text {th }}$ Sprint & 8.49 & 2524 & \pm & 397 & 99 & \pm & 16 & 96 & \pm & 6 & 1.2 & \pm & 0.03 & 166 & I & $0^{*}$ & 87 & \pm & 0 & high-intensity \\
\hline $6^{\text {th }}$ Sprint & 8.37 & 2523 & \pm & 310 & 99 & \pm & 12 & 92 & I & 8 & 1.2 & \pm & 0.04 & 166 & I & 1 & 87 & \pm & 0 & high-intensity \\
\hline $7^{\text {th }}$ Sprint & 8.14 & 2484 & \pm & 533 & 98 & \pm & 21 & 78 & \pm & 19 & 1.2 & \pm & $0.03 *$ & 162 & \pm & $1 *$ & 85 & \pm & 0 & low-intensity \\
\hline Recovery & & 822 & \pm & 431 & 32 & $D^{-1}$ & 17 & 35 & $| \pm|$ & 18 & 1.4 & \pm & 0.34 & 103 & \pm & 8 & 54 & \pm & 2 & passive recover \\
\hline
\end{tabular}

$*=\mathrm{p}<0.001$ with previous sprinut

maximal effort: $>95 \% \mathrm{HR}_{\max }$

high-intensity: $86-95 \% \mathrm{HR}_{\max }$

low-intensity: $76-85 \% \mathrm{HR}_{\max }$

active recovery: $65-75 \% \mathrm{HR}_{\mathrm{m}}$

passive recovery: $\leq 65 \% \mathrm{HR}_{\max }$ 


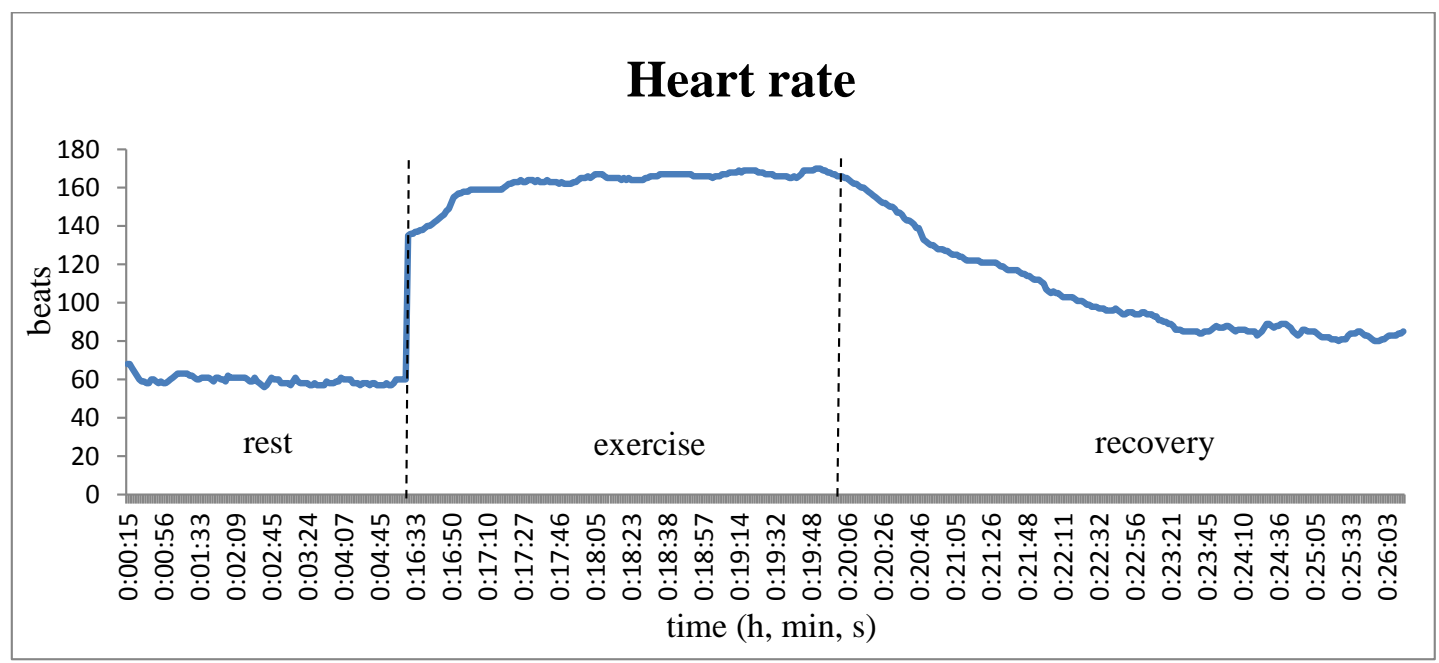

Fig. (2). Heart rate curve before, during, and after Repeated Sprint Ability test.

Table 2. Energy cost and energy source contribution during Repeated Sprint Ability test.

\begin{tabular}{|c|c|c|c|c|}
\hline & Percentuage & kcal & kj & $\mathbf{L O}_{2}{ }^{-1}$ \\
\hline Aerobic & 80.3 & 39.9 & 166.6 & 8.0 \\
\hline Anaerobic Lactid & 19.2 & 9.5 & 39.9 & 1.9 \\
\hline Anaerobic Alactid & 0.5 & 0.3 & 1.1 & 0.1 \\
\hline Total & 100 & 49.7 & 207.9 & 9.9 \\
\hline
\end{tabular}

\section{DISCUSSION}

The main finding of this study was that the studied RSAt posed high demands on the female soccer players, sustained mainly by the aerobic metabolism compared to the anaerobic metabolism. Bradley and Vescovi [14] showed that the number of high-intensity repeated-sprint bouts performed during a male and female soccer match, is one of the major factors that discriminate the elite from a sub-elite level competition. Study of Bishop and Edge [26] on repeated-sprint ability in female recreational team-sport athletes (netball, basketball and field hockey) showed that the ability to minimize fatigue was related to increased performance. Quality of alternation between deceleration and acceleration phase plays an important role in a match [27]. The study by Nikolaidis et al. [28] on soccer players showed the existence of different physical fitness components that are related to each phase of RSA.

Considering that various protocols have been used in the literature to evaluate the RSA, it is difficult to compare the results between studies. We decided to conduct the test proposed by Bangsbo et al. [15] because it is easy, and commonly used in researches on RSA in soccer. We have previously used it and, for this reason, we had data about male Italian soccer players for comparison. In fact, compared to the study by Perroni et al. [29] on semi-professional male soccer players, our data showed worst values in Total Time $(+20.8 \%)$ but better in IF\% (-4,5\%). A similar trend (higher TT but lower IF\%) was observed compared to our case study $[9,10]$ on professional and amateur male soccer players of different countries. The inability to maintain repeated-sprint performance has been attributed to i) increase in lactate [30], ii) accumulation of $\mathrm{H}+[6]$, iii) depletion of muscle phosphocreatine [31], and iv) changes in the neuromuscular coordination of muscle contraction [32]. In addition, potassium and calcium accumulation is a major contributor to reduced membrane excitability and conduction velocity during fatiguing muscle contraction [33, 34].

Previous studies $[35,36]$ have highlighted $\mathrm{VO}_{2 \max }$ and the velocity at the onset of blood lactate accumulation as important physical fitness components for soccer players. Various studies $[37,38]$ reported a moderate and/or no correlation of $\mathrm{VO}_{2 \max }$ with RSA and with the ability of skeletal muscle to recover after anaerobic exercise. In literature, the use of $\mathrm{VO}_{2 \max }$ as a useful indicator of RSA has contrasting considerations and it appears linked to the type of protocol used. Aziz et al. [37] and Bishop et al. [38] reported a relationship between $\mathrm{VO}_{2 \max }$ and RSA when sprints of less than $40 \mathrm{~m}$ (or 6 seconds) were used. Da Silva et al. [10] found that both velocity at $\mathrm{VO}_{2 \max }$ and the minimum velocity needed to reach $\mathrm{VO}_{2 \max }$ negatively correlated with the mean time to complete $7 \times 34.2-\mathrm{m}$ sprints, and Dupont et al. [39] reported a positive correlation between the time constant for the fast component of $\mathrm{VO}_{2}$ kinetics and the total time to complete $15 \times 40 \mathrm{~m}$ sprints. In this way, Balsom et al. [40] showed that the length of the sprints could alter the contribution of the aerobic system. In this study, the energy system contributions during exercise were calculated using the software GEDAE-LaB, free open-source software online (http://www.gedaelab.org) with an easy-to-use interface available, with the need for downloading, registration or login. Results of our study showed that $\mathrm{VO}_{2}$ increased during RSAt from the first to the last maximal sprint and this trend was in line with the previous study of McGawley and Bishop [41]. Previous studies [41, 42], based on mathematical models of metabolic energy production during short (10 s or less) maximal sprints, suggested that $3-8 \%$ of the energy required is derived from aerobic sources. Contrarily, the present study measured $\mathrm{VO}_{2}$ directly, and found a contribution by aerobic mechanism of $80 \%$ to all exercise (total time $=58.71 \mathrm{~s}$ ). Therefore, this data suggests that the recovery among sprint is fuelled by aerobic metabolism, and it plays an important role in the removal of accumulated lactate and the replenishment of CP stores $[43,44]$. 
$\mathrm{VO}_{2}$ kinetics have contributed to the understanding of physiological adjustments over time, such as muscle metabolism and systemic oxygen transport. These results were in accordance with the study by Engelen et al. [44] who showed that the HR response during heavy exercise had a similar but not identical appearance to $\mathrm{VO}_{2}$ due to different kinetics. In this study, we found that $\mathrm{VO}_{2}$ reached the peak when HR was still rising, and their average was around $85 \%$ of maximal values. These values were similar to those reported by a considerable number of scientific studies in high-intensity activities. Better aerobic fitness level is associated with high external training/match loads and can improve tolerance to fatigue in high-intensity activities, suggesting a better ability to maintain physical performance for a prolonged period.

\section{LIMITATION AND APPLICATION}

The main limitation of the study is the lack of other female soccer players with the same background to our case study to increase the knowledge about energy source contributions during RSAt. The strength of this case study is the novelty to have metabolically evaluated in detail a simply test, analysed in literature and used by the trainer for their simple protocol and economic tools (stopwatch and heart rate monitor). Considering that that $\mathrm{VO}_{2 \max }$ and HR kinetics have a different increase in time, the trainers have to be informed on how to improve the performance.

For these reasons, further largescale studies are recommended to analyse how aerobic and anaerobic systems can be influenced by differences in the type of protocol to use for the RSA test (i.e. length of the sprints, bout, Change of direction).

\section{CONCLUSION}

To our knowledge, only few studies $[26,38]$ investigated $\dot{\mathrm{V}}_{2}$ and the contribution of energy source during a repeated sprint test in female soccer players. Aerobic and anaerobic capacities of an athlete may determine the outcome of the competition and it is, therefore, important to evaluate them. Considering that the energy consumption during intermittent exercises (anaerobic and aerobic) requires different metabolism as a result of physiological stimuli proposed, the present findings substantiate the need to choose specific and adequate training methods for female soccer players that aim at increasing their RSA performances. A regular (i.e. every 2 months) and adequate (i.e. type of protocol, bout, length of the sprints) RSA testing provides a baseline for future comparison and assists in establishing personalized training programme. This would have important implications for the design of training programs to improve the ability to recover from high-intensity running and sprinting and decrease fatigue that has a detrimental effect on technical performance [2].

\section{DISCLOSURE STATEMENT}

No potential conflict of interest was reported by the authors.

\section{ETHICS APPROVAL AND CONSENT TO PARTICIPATE}

The study was approved by the Institutional Review Board of eCampus University.

\section{HUMAN AND ANIMAL RIGHTS}

No animals were used for this study. All humans research procedures performed in the current study were in accordance with the ethical standards of the institutional and/or national research committee and with the 1964 Helsinki declaration and its later amendments or comparable ethical standards.

\section{CONSENT FOR PUBLICATION}

All participants were informed about the protocol and gave their written informed consent before participating in the study.

\section{CONFLICT OF INTEREST}

The author declares no conflict of interest, financial or otherwise.

\section{FUNDING}

There was no financial support for this study.

\section{ACKNOWLEDGEMENTS}

Declared none.

\section{REFERENCES}

[1] Rampinini E, Impellizzeri FM, Castagna C, Azzalin A, Ferrari Bravo D, Wisløff U. Effect of match-related fatigue on short-passing ability in young soccer players. Med Sci Sports Exerc 2008; 40(5): 934-42. [http://dx.doi.org/10.1249/MSS.0b013e3181666eb8] [PMID: 18408 603]

[2] Mohr M, Krustrup P, Andersson H, Kirkendal D, Bangsbo J. Match activities of elite women soccer players at different performance levels. J Strength Cond Res 2008; 22(2): 341-9. [http://dx.doi.org/10.1519/JSC.0b013e318165fef6] [PMID: 18550946]

[3] Girard O, Mendez-Villanueva A, Bishop D. Repeated-sprint ability part I: factors contributing to fatigue. Sports Med 2011; 41(8): 673-94. [http://dx.doi.org/10.2165/11590550-000000000-00000] [PMID: 2178 0851]

[4] Mara JK, Thompson KG, Pumpa KL. Physical and physiological characteristics of various-sided games in elite women's soccer. Int J Sports Physiol Perform 2016; 11(7): 953-8.

[http://dx.doi.org/10.1123/IJSPP.2015-0087] [PMID: 26872150]

[5] Meylan CM, Trewin J, McKean K. Quantifying explosive actions in international women's soccer. Int J Sports Physiol Perform 2016; 1-20. [PMID: 27295719]

[6] Glaister M. Multiple sprint work: Physiological responses, mechanisms of fatigue and the influence of aerobic fitness. Sports Med 2005; 35(9): 757-77.

[http://dx.doi.org/10.2165/00007256-200535090-00003] [PMID: 1613 8786]

[7] Spencer M, Bishop D, Dawson B, Goodman C. Physiological and metabolic responses of repeated-sprint activities: Specific to fieldbased team sports. Sports Med 2005; 35(12): 1025-44. [http://dx.doi.org/10.2165/00007256-200535120-00003] [PMID: 1633 6007]

[8] di Prampero PE, Fusi S, Sepulcri L, Morin JB, Belli A, Antonutto G. Sprint running: a new energetic approach. J Exp Biol 2005; 208(Pt 14): $2809-16$

[http://dx.doi.org/10.1242/jeb.01700] [PMID: 16000549]

[9] Chaouachi A, Manzi V, Wong P, et al. Intermittent endurance and repeated sprint ability in soccer players. J Strength Cond Res 2010; 24(10): 2663-9.

[http://dx.doi.org/10.1519/JSC.0b013e3181e347f4] [PMID: 20847706]

[10] da Silva JF, Guglielmo LGA, Bishop D. Relationship between different measures of aerobic fitness and repeated-sprint ability in elite soccer players. J Strength Cond Res 2010; 24(8): 2115-21.

[http://dx.doi.org/10.1519/JSC.0b013e3181e34794] [PMID: 206136 44]

[11] Fahmy M. Increase participation and competitions 2011. http://www. fifa.com $/ \mathrm{mm} /$ document/footballdevelopment/women/ 01/51/51/64/preentation_increaseparticipation_e.pdf

[12] Lohmander LS, Östenberg A, Englund M, Roos H. High prevalence of 
knee osteoarthritis, pain, and functional limitations in female soccer players twelve years after anterior cruciate ligament injury. Arthritis Rheum 2004; 50(10): 3145-52.

[http://dx.doi.org/10.1002/art.20589] [PMID: 15476248]

[13] UEFA. 2017.Women's football across the national associations available on http://www.uefa.com/MultimediaFiles /Download/OfficialDocument/uefaorg/Women'sfootball/02/51/60/57/2516057_DOW NLOAD.pdf

[14] Bradley PS, Vescovi JD. Velocity thresholds for women's soccer matches: sex specificity dictates high-speed running and sprinting thresholds - Female Athletes in Motion (FAiM). Int J Sports Physiol Perform 2015; 10(1): 112-6

[http://dx.doi.org/10.1123/ijspp.2014-0212] [PMID: 25203354]

[15] Bangsbo J, Nørregaard L, Thorsø F. Activity profile of competition soccer. Can J Sport Sci 1991; 16(2): 110-6. [PMID: 1647856]

[16] Stiles VH, James IT, Dixon SJ, Guisasola IN. Natural turf surfaces: the case for continued research. Sports Med 2009; 39(1): 65-84. [http://dx.doi.org/10.2165/00007256-200939010-00005] [PMID: 1909 3696]

[17] Bertuzzi R, Melegati J, Bueno S, et al. GEDAE-LaB: A free software to calculate the energy system contributions during exercise. PLoS One 2016; 11(1): e 0145733 .

[http://dx.doi.org/10.1371/journal.pone.0145733] [PMID: 26727499]

[18] Bertuzzi RC, Franchini E, Kokubun E, Kiss MA. Energy system contributions in indoor rock climbing. Eur J Appl Physiol 2007; 101(3): 293-300

[http://dx.doi.org/10.1007/s00421-007-0501-0] [PMID: 17602238]

[19] Guidetti L, Emerenziani GP, Gallotta MC, Da Silva SG, Baldari C. Energy cost and energy sources of a ballet dance exercise in female adolescents with different technical ability. Eur J Appl Physiol 2008; 103(3): 315-21

[http://dx.doi.org/10.1007/s00421-008-0705-y] [PMID: 18340457]

[20] Helsen W, Bultynck JB. Physical and perceptual-cognitive demands of top-class refereeing in association football. J Sports Sci 2004; 22(2): $179-89$

[http://dx.doi.org/10.1080/02640410310001641502] [PMID: 14998 096]

[21] Fitzsimons M, Dawson B, Ward D, Wilkinson A. Cycling and running tests of repeated sprint ability. Aust J Sci Med Sport 1993; 25: 82-7.

[22] Guidetti L, Meucci M, Bolletta F, Emerenziani GP, Gallotta MC, Baldari Validity C. Reliability and minimum detectable change of COSMED K5 portable gas exchange system in breath-by-breath mode. Plos One 2018.

[23] Baldari C, Bonavolontà V, Emerenziani GP, Gallotta MC, Silva AJ, Guidetti L. Accuracy, reliability, linearity of Accutrend and Lactate Pro versus EBIO plus analyzer. Eur J Appl Physiol 2009; 107(1): 105-11.

[http://dx.doi.org/10.1007/s00421-009-1107-5] [PMID: 19526366]

[24] Jetté M, Sidney K, Blümchen G. Metabolic equivalents (METS) in exercise testing, exercise prescription, and evaluation of functional capacity. Clin Cardiol 1990; 13(8): 555-65.

[http://dx.doi.org/10.1002/clc.4960130809] [PMID: 2204507]

[25] Ozyener F, Rossiter HB, Ward SA, Whipp BJ. Influence of exercise intensity on the on- and off-transient kinetics of pulmonary oxygen uptake in humans. J Physiol 2001; 533(Pt 3): 891-902. [http://dx.doi.org/10.1111/j.1469-7793.2001.t01-1-00891.x] [PMID: 11410644]

[26] Bishop D, Edge J. Determinants of repeated-sprint ability in females matched for single-sprint performance. Eur J Appl Physiol 2006; 97(4): 373-9.

[http://dx.doi.org/10.1007/s00421-006-0182-0] [PMID: 16612646]

[27] Lakomy J, Haydon DT. The effects of enforced, rapid deceleration on performance in a multiple sprint test. J Strength Cond Res 2004; 18(3): 579-83.

[PMID: 15320690]

[28] Nikolaidis PTA, Dellal A, Torres-Luque G, Ingebrigtsen J. Determinants of acceleration and maximum speed phase of repeated sprint ability in soccer players: A cross-sectional. Sci Sports 2015;
30(1): e7-e16.

[http://dx.doi.org/10.1016/j.scispo.2014.05.003]

[29] Perroni F, Corvino M, Cignitti L, Minganti C. RSA response to preseason training in semi professional soccer players. Sport Sci Health 2013; 9(2): 59-64.

[http://dx.doi.org/10.1007/s11332-013-0146-9]

[30] Thomas C, Sirvent P, Perrey S, Raynaud E, Mercier J. Relationships between maximal muscle oxidative capacity and blood lactate removal after supramaximal exercise and fatigue indexes in humans. J Appl Physiol 2004; 97(6): 2132-8.

[http://dx.doi.org/10.1152/japplphysiol.00387.2004] [PMID: 15208 291]

[31] Gaitanos GC, Williams C, Boobis LH, Brooks S. Human muscle metabolism during intermittent maximal exercise. J Appl Physiol 1993; 75(2): 712-9

[http://dx.doi.org/10.1152/jappl.1993.75.2.712] [PMID: 8226473]

[32] Mendez-Villanueva A, Hamer P, Bishop D. Physical fitness and performance. Fatigue responses during repeated sprints matched for initial mechanical output. Med Sci Sports Exerc 2007; 39(12): 2219-25.

[http://dx.doi.org/10.1249/mss.0b013e31815669dc] [PMID: 18046 194]

[33] Fortune E, Lowery MM. Effect of extracellular potassium accumulation on muscle fiber conduction velocity: a simulation study. Ann Biomed Eng 2009; 37(10): 2105-17

[http://dx.doi.org/10.1007/s10439-009-9756-4] [PMID: 19588250]

[34] Allen DG, Westerblad H. Role of phosphate and calcium stores in muscle fatigue. J Physiol 2001; 536(Pt 3): 657-65.

[http://dx.doi.org/10.1111/j.1469-7793.2001.t01-1-00657.x] [PMID: 11691862]

[35] Helgerud J, Engen LC, Wisloff U, Hoff J. Aerobic endurance training improves soccer performance. Med Sci Sports Exerc 2001; 33(11): 1925-31.

[http://dx.doi.org/10.1097/00005768-200111000-00019] [PMID: 1168 9745]

[36] Impellizzeri FM, Rampinini E, Marcora SM. Physiological assessment of aerobic training in soccer. J Sports Sci 2005; 23(6): 583-92. [http://dx.doi.org/10.1080/02640410400021278] [PMID: 16195007]

[37] Aziz AR, Chia M, Teh KC. The relationship between maximal oxygen uptake and repeated sprint performance indices in field hockey and soccer players. J Sports Med Phys Fitness 2000; 40(3): 195-200. [PMID: 11125761]

[38] Bishop D, Edge J, Goodman C. Muscle buffer capacity and aerobic fitness are associated with repeated-sprint ability in women. Eur J Appl Physiol 2004; 92(4-5): 540-7.

[http://dx.doi.org/10.1007/s00421-004-1150-1] [PMID: 15168128]

[39] Dupont G, Millet GP, Guinhouya C, Berthoin S. Relationship between oxygen uptake kinetics and performance in repeated running sprints. Eur J Appl Physiol 2005; 95(1): 27-34

[http://dx.doi.org/10.1007/s00421-005-1382-8] [PMID: 15976999]

[40] Balsom PD, Seger JY, Sjödin B, Ekblom B. Maximal-intensity intermittent exercise: effect of recovery duration. Int J Sports Med 1992; 13(7): 528-33.

[http://dx.doi.org/10.1055/s-2007-1021311] [PMID: 1459748]

[41] McGawley K, Bishop DJ. Oxygen uptake during repeated-sprint exercise. J Sci Med Sport 2015; 18(2): 214-8.

[http://dx.doi.org/10.1016/j.jsams.2014.02.002] [PMID: 24602687]

[42] Péronnet F, Thibault G. Mathematical analysis of running performance and world running records. J Appl Physiol 1989; 67(1): 453-65. [http://dx.doi.org/10.1152/jappl.1989.67.1.453] [PMID: 2759974]

[43] Gastin PB. Energy system interaction and relative contribution during maximal exercise. Sports Med 2001; 31(10): 725-41.

[http://dx.doi.org/10.2165/00007256-200131100-00003] [PMID: 1154 7894]

[44] Engelen M, Porszasz J, Riley M, Wasserman K, Maehara K, Barstow TJ. Effects of hypoxic hypoxia on $\mathrm{O}_{2}$ uptake and heart rate kinetics during heavy exercise. J Appl Physiol 1996; 81(6): 2500-8. [http://dx.doi.org/10.1152/jappl.1996.81.6.2500] [PMID: 9018498] 